\title{
Erratum zu: Thermophysikalische Stoffwerte von Fluiden für Kältebäder, von wässrigen Lösungen und Glykolen
}

Gernot Krakat

\section{Erratum zu:}

Kapitel D4.2 in: P. Stephan et al. (Hrsg.), VDI-Wärmeatlas, Springer Reference Technik, VDI Springer Reference, https://doi.org/10.1007/978-3-662-52989-8_23

Kapitel D4.2: Die Angaben der Spalten-Überschrift „dynamische Viskosität“ in den Tabellen Tab. 2 und Tab. 4 wurden korrigiert und in $10^{-3} \mathrm{Ns} / \mathrm{m}^{2}$ geändert. 